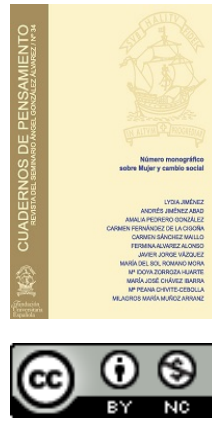

Cuadernos de pensamiento 34 Publicación del Seminario "Ángel González Álvarez" de la Fundación Universitaria Española Número monográfico sobre Mujer y cambio social Año 2021

\title{
Del feminismo a un nuevo humanismo
}

\author{
From Feminism to a New Humanism
}

\author{
Ma IDOYA ZORROZA \\ Universidad Pont. de Salamanca \\ Facultad de Educación \\ Salamanca. España \\ ID ORCID 0000-0002-3195-4101 \\ izorrozahu@upsa.es
}

Recibido: 03-08-2021 | Revisado: 08-10-2021

Aceptado: 14-10-2021 | Publicado: 30/12/2021

DOI: https://doi.org/10.51743/cpe.227

RESUMEN: Este trabajo no realiza una historia del feminismo, sino un análisis crítico de las direcciones generales que éste ha tomado. El motivo principal es que el feminismo ha creado una situación de perplejidad y confusión por el que muchas mujeres tienen una ambigua valoración de este movimiento. Esto se debe, por un lado, a la aceptación general de los logros conquistados para la presencia de las mujeres en espacios políticos, sociales, educativos o laborales en aras a construir una sociedad sin desigualdad por razón de género; sin embargo, muchas rechazan abiertamente la ideología feminista en sus planteamientos y consecuencias. Esto se debe a las implicaciones ideológicas de los nuevos feminismos. Se muestran las consecuencias del cambio de paradigma en el feminismo y su revisión desde la proyección de una antropología integral que apuesta teóricamente o por un feminismo de nuevo cuño o, mejor, por un humanismo integrador. 
PALABRAS ClAVE: Antropología, derechos, feminismo, feminista, ideología, humanismo, ideología, mujer.

ABSTRACT: This work does not carry out a history of feminism, but rather a critical analysis of its general directions. The main reason: feminism has created a situation of perplexity and confusion. Many women (famous and influential or not) have an ambiguous assessment about feminism; they assume the political, social, educational or professional achievements and their universal defence. But they openly reject feminism as an ideology in its approaches and consequences. The article shows the consequences of the modern and postmodern paradigm in feminism and the needs for human beings following integral anthropology. In conclusion, it defends theoretically or new feminism or, better, for integrative humanism.

KEYWORDS: Anthropology, feminism, feminist, humanism, ideology, rights, woman.

\section{UN PANORAMA COMPLEJO}

Oon mayor o menor fortuna, la bandera del feminismo ondea como crítica y como propuesta. Desde la primera Déclaration des droits de la femme et de la citoyenne, por Olympe de Gouges en 1791 - que buscaba que las mujeres fueran consideradas, en deberes y derechos, iguales a los varones - , hasta el presente, son muchos los ríos de tinta, e incluso sangre, vertidos por la dignidad y derechos de la mujer. Muchos de los objetivos de la declaración de 1791 se han cumplido, otros todavía no han encontrado una solución satisfactoria ${ }^{1}$.

\footnotetext{
${ }^{1}$ La Declaración de 1791 partía de la idea de que pese a la diferencia de naturaleza, la dignidad y roles ante la sociedad y el derecho debían ser de igualdad: "La mujer nace libre y permanece igual al hombre en derechos. Las distinciones sociales sólo pueden estar fundadas en la utilidad común"; "los derechos naturales e imprescriptibles de la Mujer y del Hombre [...] son la libertad, la propiedad, la seguridad y, sobre todo, la resistencia a la opresión"; "todas las Ciudadanas y Ciudadanos deben participar en su formación personalmente o por medio de sus representantes. Debe ser la misma para todos; todas las ciudadanas y todos los ciudadanos, por ser iguales a sus ojos, deben ser igualmente admisibles a todas las dignidades, puestos y empleos públicos, según sus capacidades y sin más distinción que la de sus virtudes y sus talentos”, etc.
} 
Los logros conseguidos - avances realizados no sin retrocesos en algunos momentos y lugares-, han incorporado a la mujer a amplios sectores de la vida política, social y empresarial. Ya no es sorprendente encontrar mujeres en sedes judiciales, ejerciendo labores profesionales de gran esfuerzo y resistencia por tierra, mar y aire, en la Universidad y al volante de máquinas de gran tonelaje, al frente de empresas familiares y de grandes internacionales, al cargo de ministerios e incluso representando y gobernando a países enteros.

Sin embargo, las estadísticas siguen ofreciendo cifras desalentadoras: dificultades de acceso a la educación, sanidad e independencia jurídica en muchos países - especialmente en países en vías de desarrollo o coartados por presiones religiosas - desempleo mayoritariamente femenino en tiempo de crisis, violencia sexista —e incluso justificación y "normalización" de comportamientos denigrantes contra la mujer-, su cosificación en los medios culturales y de entretenimiento, techos de cristal no explícitos en determinados ámbitos laborales, discriminaciones salariales por cuestión de sexo, presión social para retrasar por motivos laborales la formación de una familia, o dificultades no explícitas para su acceso al mercado laboral por el mismo motivo ${ }^{2}$, etc.

${ }^{2}$ Por poner un ejemplo, a la Declaración de 1791 le siguió la Vindication of the Right of Women (1792). La ONU declaró en 1967 la Declaración sobre la Eliminación de la discriminación contra la mujer; 1975 fue el Año Internacional de la Mujer donde se aprobó el primer plan de acción mundial y el Decenio de las Naciones Unidas para la Mujer: Igualdad, Desarrollo y Paz. En 1995 tuvo lugar la Declaración y Plataforma de Acción de Beijing, de la ONU. La Asamblea General de las Naciones Unidas del año 2000, dio el título La mujer en el año 2000: igualdad entre los géneros, desarrollo y paz para el siglo XXI. Esa igualdad fue un objetivo para la ONU (2002-7) con logros limitados según el informe de la UNESCO, Gender equality in basic education in Latin America and the Caribbean: state of the art (Chile, 2002) y evaluado en cuanto a Educación en el Informe de Seguimiento de la EPT en el mundo 2009. Superar la desigualdad (París, 2009). Y pese a ser la igualdad de sexos un Objetivo de Desarrollo Sostenible de aquí a 2030, siendo optimistas se necesitará todavía mucho para lograrlo según el Global Gender Gap Report 2020 elaborado por el World Economic Forum. En el caso de España, el más reciente es el estudio del Instituto Nacional de Estadística Mujeres y hombres en España que analiza en el 2021 la brecha entre sexos en: 1) empleo, 2) salarios, ingresos, cohesión social 3) educación, 4) salud, 5) conciliación trabajo y familia, 6) ciencia y tecnología, sociedad de la información, 7) delito y violencia, y 8) poder y toma de decisiones (INE, 2020). 
Son luces y sombras de nuestro tiempo: la herencia ganada gracias a la lucha de generaciones de mujeres bajo la bandera del feminismo, o la prueba de que, a la altura de nuestro tiempo, todavía tenga sentido como movimiento social y de reivindicación para que se eliminen muchos obstáculos que impiden la contribución de muchas mujeres a la sociedad y al espacio público.

Debe decirse, además, que a comienzos del siglo XXI el feminismo vive una situación de gran complejidad alentada por la evolución interna de las ideas que la han configurado en su historia. La gran cantidad de estudios y trabajos que se elaboran califican la adjetivación de cátedras y disciplinas, o la creación de estudios diferenciados ${ }^{3}$. Y a su vez generan una gran confusión pues, como se ha afirmado, es "el nuestro un tiempo en que abunda la literatura de género $[. .$.$] pero guiada, en general, por una brújula alocada que$ no sabe bien dónde marcar el norte de la verdad" (Riego de Moine, 2008, p. 267; Cf. Roig, 1986, pp. 19 ss.). Así le cabe propiamente la adscripción de panorama complejo.

De hecho, hoy propiamente no puede hablarse en sentido propio de feminismo sino de múltiples y variados feminismos, sometidos cada uno de ellos a distintas valoraciones (Caballé, 2013, p. 24; Freedman, 2004, p. 15).

Si bien a lo largo de estos más de 200 años la lucha por los derechos de las mujeres no ha dejado de defenderse en los distintos foros (políticos, sociales, laborales, internacionales, educación, derechos dinásti$\cos .$. ), esta defensa no se ha hecho -ni individual ni colectivamentebajo una misma bandera (Saranyana, 2001). Ella acoge, a grandes rasgos, un feminismo (tradicional) que busca la igualdad de oportunidades y de derechos a nivel social y jurídico, por un lado; frente a un nuevo feminismo que ha ido autoexplicitándose asumiendo paradigmas e ideales modernos o postmodernos de diverso cuño (socialismo, marxismo, constructivismo, postmodernismo...).

\footnotetext{
${ }^{3}$ No con la extensión que tiene en los Estados Unidos (con más de 35 centros que ofrecen estudios de grado, máster y doctorado específicos), también en España se han creado Institutos o Centros de estudios de la mujer de los que dependen titulaciones de Máster; hay también al menos un programa de doctorado específico.
} 
El nuestro es un panorama complejo también por los cambios de dirección que han sufrido las reivindicaciones que bajo esa denominación se han reclamado.

a) La lucha feminista (tradicional) tenía en su punto de partida el objetivo de superar una desigualdad de reconocimiento en la participación de la mujer en los órdenes propiamente civiles, económicos y políticos, asumiendo y reivindicando las consignas ilustradas de libertad e igualdad, no ya como eliminación de una división por clases sociales, sino como supresión de una diferencia más profunda entre géneros. Esto se hacía con la petición del voto, es decir: la consideración de que el género no ha de ser un criterio selectivo para la participación pública en la sociedad (poniendo en el voto el modo privilegiado de participación en la res-publica ${ }^{4}$ ), la eliminación de trabas para poder asumir cargos de responsabilidad, o el ejercicio de actividades que otorgaran autonomía económica (figurar en contratos, abrir cuentas bancarias, firmar documentos sobre bienes propios, sin la tutela de padres, esposos o hijos), en la línea de una reivindicación de derechos, roles, responsabilidades y beneficios en planos de igualdad a los reconocidos al género masculino.

b) Esta lucha ha asumido posteriormente, desde el siglo XX, objetivos distintos. Las reivindicaciones más contemporáneas incluyen reestructuraciones lingüísticas no sexistas (que incluyan a todos, todas, todes, todxs, tod@s... haciendo una violencia política al idioma), la eliminación de diferencias por sexo en juguetes, la lucha por los denominados 'derechos reproductivos' o la ruptura en lo humano entre sexo y género, suprimiendo todo necesitarismo genérico y haciéndolo de él una opción cultural, susceptible de ser reinterpretada y modificada. Detrás de estas nuevas reclamaciones se reafirma una larvada y radical división de la sociedad en clases, genealógicamente confirmada en su historia, interpretándolas desde los nuevos parámetros aportados filosóficamente por distintas imágenes del ser humano: marxista, socialista, psicoanalista, constructivista, postmoderna... (Roig,

\footnotetext{
${ }^{4}$ Por ejemplo, el acceso de la mujer al voto abarca un abanico de fechas que van desde 1869 en algunos estados de los Estados Unidos de América, a 1971 en Suiza; pero no sigue siendo un derecho universal (Solé Romeo, 2011, pp. 111-112; Caballé, 2013; De Diego, 2008).
} 
1986; Solé Romero, 2011; y en el caso de España: Caballé, 2013; De Diego, 2008; Agustín Puerta, 2003; Folguera, 1988).

La diferencia de estos dos niveles en el feminismo ha derivado, en nuestros tiempos, en una confusión también en su valoración: desde la aprobación de la reivindicación de un acceso a unos derechos y funciones ejercidos en exclusiva por varones para extenderlos también a las mujeres, hasta la discusión abierta por los intentos de plantear la relación entre géneros desde la oposición -lucha de términos irreconciliables-, la dialéctica, y la crítica global a la cultura occidental como sistema de violencia y opresión a la mujer, buscando una deconstrucción de la cultura, el lenguaje, los imaginarios sociales, etc., interpretados como cristalización de una dinámica de lucha de poderes y de opresión de un género sobre otro ${ }^{5}$.

En suma, hoy no es posible hablar del feminismo, sino a lo más de feminismos: cultural, liberal, radical, ecofeminismo, de la igualdad, de la diferencia, marxista, socialista, separatista, filosófico, psicoanalítico, estructuralista, constructivista, queer, transfeminismo, feminismo salvaje, ensimismado, disidente, biofeminismo... Todos ellos y algunos más son nombres que nos posicionan ante un mapa complejo (Solé Romero, 2011; Ritzer, 2005).

No se busca aquí realizar una historia del feminismo, sino analizar críticamente una situación que provoca perplejidad y confusión, como es la ambigua valoración por parte de las mujeres del feminismo, la advertencia de un cambio de paradigma en él y su revisión desde la proyección de una antropología integral que apuesta teóricamente no por un feminismo de nuevo cuño sino, mejor, por un humanismo integrador.

\footnotetext{
${ }^{5}$ Esta alianza, por otro lado, se considera crítica e incluso perjudicial para las iniciativas positivas y futuras del feminismo, pues "un sector del feminismo ha establecido una alianza intelectual y política con la postmodernidad al concluir que esta corriente interpreta más adecuadamente la realidad y ofrece una estrategia política más incluyente y menos normativa. De otro lado, el pensamiento feminista que se inscribe en la tradición de la igualdad ha señalado que la postmodernidad no ha proporcionado al feminismo ninguna herramienta crítica nueva" nos dice Cobo (2002, pp. 55-77; cfr. también: Gallego Pérez de Sevilla, 2018, pp. 361-394). El contexto teórico de la postmodernidad introduce al feminismo en una dialéctica de la oposición que distorsiona la realidad antropológica básica.
} 


\section{UNA SITUACIÓN CONFUSA}

En su historia, el feminismo ha ido buscando la igualdad de tratamiento, derechos y oportunidades histórica y tradicionalmente representadas por los hombres, buscando que la diferencia de género no supusiera una diferencia o merma en dichos derechos atribuibles al ser humano en general.

Esto implica combatir la idea de que toda diferencia de roles culturales y sociales asignados a la mujer, que incluyen una minusvaloración de su capacidad para gobernar y realizar su propia vida y participar en las instituciones en régimen de igualdad de derechos -históricamente justificada porque la mujer se la consideraba dependiente del varón por motivos biológicos, psicológicos o incluso antropológicos y metafísicos-, se debía efectivamente a una diferencia esencial con respecto del varón. Desde la medicina aristotélico-galénica griega que consideraba a la mujer como un varón imperfecto, a la justificación filosófica de los idealistas alemanes que consagran una infravaloración de la mujer apoyada por argumentos psicológicos y metafísicos, se convierten en leyes necesarias lo que eran costumbres impuestas culturalmente por sociedades desiguales. Esa desigualdad en dignidad y derechos ha sido una barrera que superar, y en su derribo se han invertido las existencias y energías de generaciones de mujeres (Roig, 1986, pp. 21-24).

Pero buscando suprimir las diferencias socio-políticas entre varón y mujer se han intercalado metas y objetivos concretos que para algunas mujeres son, en muchas ocasiones, cuestionables ${ }^{6}$, como la exigencia de asumir en exclusividad valores, roles y actitudes tradicionalmente masculinas (dar preferencia al mundo profesional frente al familiar, o incluso renunciar a todo proyecto familiar; la negación de la maternidad o la alteración de tiempos y ciclos en subordinación a proyectos artificiales y externos...). Con otras pa-

${ }^{6}$ El elemento combativo de los primeros años, cuando se desmontaba una estructura social apoyada en la reserva de privilegios universales sólo para los varones (como el acceso a la educación básica o superior, la autonomía económica, etc.) pudo derivar en algunos movimientos en una posición dialéctica de oposición y enfrentamiento entre géneros. Como señalaba Solé (2011, p. 19), debería distinguirse el movimiento que buscaba destruir una estructura de privilegios selectiva, de aquél que plantea la supresión de toda diferencia en una eterna oposición entre varones y mujeres, y de relaciones de poder entre ellos: ser "promujer pero no antihombre", busca "destruir la jerarquía masculina, no el dualismo sexual". 
labras, la masculinización de la mujer: objetivo buscado por algunas ramas del feminismo y neofeminismo ${ }^{7}$. O el intento de quebrar toda determinación de género en un imaginario plural, constructivista y fluido -huyendo siempre de una versión bipolar-, como es expresado en la noticia que llegaba a los medios durante el 2020: la red social Facebook ofrece a los ciudadanos británicos 71 opciones de género distintas $^{8}$, haciendo de la identidad un "patchwork" construido de fragmentos identitarios sacados de las revistas, las redes, los resultados performativos de quienes quieren vivir haciendo de su vida un arte-espectáculo, etc. (Sanz, 2018, p. 105).

Sin embargo, para una mujer de hoy en día, ¿qué significa el feminismo?

Podría servirnos como un "estado de la cuestión" un artículo publicado en un semanario español (Díaz, 11 de octubre de 2014), que ha puesto

${ }^{7}$ Han asumido que todo lo femenino es una creación cultural y proponen anularlo asumiendo modos y valores exclusivamente comprendidos como masculinos. Sin embargo, hoy en día hay un fuerte rechazo a estas versiones de feminismo, como se verá en párrafos siguientes. Así lo expresaba Polo (2015, p. 150): "Muchas veces el feminismo incurre en la aludida confusión, en que la que se desvirtúa lo que tiene la distinción sexual de positivo, y da lugar a proponer una serie de objetivos antinaturales, con lo cual se llega a la frustración, o bien la naturaleza humana se venga, pues forzar la naturaleza humana conlleva consecuencias negativas. ¿De dónde proviene esa equivocación en el asunto de la igualdad? En principio, el planteamiento de la igualdad es equivocado porque pretende una igualdad genérica, sin tener en cuenta las distinciones reales. La mujer no debe, consciente o inconscientemente, tomar como modelo al varón, lo que es un error desde muchos puntos de vista".

${ }^{8}$ Entre ellos: Asexual; Female to male trans man; Female to male transgender man; Female to male transsexual man; F2M; Gender neutral; Hermaphrodite; Intersex man; Intersex person; Intersex woman; Male to female trans woman; Male to female transgender woman; Male to female transsexual woman; Man; M2F; Polygender; T* man; T* woman; Two* person; Two-spirit person; Woman; Agender; Androgyne, Androgynes; Androgynous; Bigender; Cis; Cis Female; Cis Male; Cis Man; Cis Woman; Cisgender; Cisgender Female; Cisgender Male; Cisgender Man; Cisgender Woman; Female to Male; FTM; Gender Fluid; Gender Nonconforming; Gender Questioning; Gender Variant; Genderqueer; Intersex; Male to Female; MTF; Neither; Neutrois; Non-binary; Other; Pangender; Trans; Trans Female; Trans Male; Trans Man; Trans Person; Trans*Female; Trans*Male; Trans*Man; Trans*Person; Trans*Woman; Transexual; Transexual Female; Transexual Male; Transexual Man; Transexual Person; Transexual Woman; Transgender Female; Transgender Person; Transmasculine; Twospirit; cfr. Altera (2021). 
encima de la mesa una situación paradójica. La autora presenta las opiniones en torno al feminismo de varias mujeres que hoy son iconos por su carrera cinematográfica o musical (como Susan Sarandom, Emma Watson, Shailene Woodley, Lady Gaga, Sarah Jessica Parker, Natalie Portman, Keira Knightley, Beyoncé o Gwyneth Paltrow, entre otras). Y presenta la siguiente paradoja: en determinados sectores profesionales (la industria del cine y la música, dos ejemplos utilizados por corresponder a la profesión de las celebridades mencionadas) no hay todavía una equiparación profesional entre géneros, y además se trata de un sector criticado por vender una imagen de la mujer cosificada e irreal, lo cual justificaría el activismo en la reclamación de una verdadera igualdad y respeto entre ambos sexos. Por otro lado, hoy en día se han eliminado muchos "techos de cristal" que mostraban que la igualdad de oportunidades o de funciones en determinados sectores todavía no había sido lograda. E incluso ahora que la mujer puede determinar con gran libertad su estilo de vida, prima una versión hipersexualizada, un feminismo ensimismado (plástico y narcisista: Caballé, 2013, p. 319) que ratifica la imagen buscada por una mirada masculina (Cuenca-Piqueras et al., 2021; Abad Cadenas, 2016; Guerra Palmero, 2001) no como imposición (y consiguiente cosificación y alienación) sino como elección (y por tanto, como un ejercicio de poder y autodeterminación) (Friedan, 1974; Abad Cadenas, 2016). Aunque se alzan voces para destacar que tras ella hay un nuevo sometimiento a lo masculino (Caballé, 2013, p. 308) por cuanto lo femenino se utiliza como herramienta de poder en una dinámica de relación de género que, nuevamente, está escrita en caracteres masculinos de dominación y poder en lugar de relación y consenso.

Por otro lado, un estudio realizado sobre el tipo de lo femenino presente en bloggers o influencers (Cuenca-Piqueras et al., 2021, pp. 23 ss.) subraya que en redes no se ven reflejadas una amplia diversidad de feminidades, sino predominantemente la tradicional que proyecta la imagen (a veces irreal) de una mujer atractiva y sensual, con una familia perfecta, una mujer fuerte, exitosa, en muy buena situación económica, y que responde en grandes rasgos a los cánones de la "feminidad tradicional" (Cuenca-Piqueras et al., 2021, pp. 23, 28). 
A esto se suma, en contra, que la imagen de la feminista ha ido acumulando una serie de notas o características negativas, convirtiéndose para muchas mujeres en un anti-modelo: el rechazo de compromisos familiares y de profesiones de "cuidado" o tradicionales, la renuncia a desarrollar determinadas dimensiones — como la maternidad - en la auto-exigencia de integrarse en funciones y roles tradicionalmente masculinos adoptando sus mismos valores y rasgos de comportamiento, además de la preferencia por una presentación asexuada, descuidada, o masculinizada...

El artículo (Díaz, 11 de octubre de 2014) menciona de hecho varias opiniones de famosas que rechazan definirse como feministas o que consideran que su vida —elegida y preferida como expresión de sus objetivos y fines personales - es un anti-ejemplo del modelo feminista, porque: les gustan los hombres, asumen valores definidos como femeninos, han optado por compaginar su carrera con una familia, no renuncian a vivir la maternidad con todas sus consecuencias y a disfrutar de sus hijos, aunque eso suponga dejar de lado ocasiones de desarrollo profesional...

Todo ello revela que sobre el feminismo, quizás por la deriva de muchas prácticas reivindicatorias, grava hoy en día una acusada confusión. Considerado como el movimiento que busca defender para la mujer una igualdad de derechos ya reales para los hombres, pocas personas rechazarían ser consideradas tales. Visto desde la perspectiva de la búsqueda de igualdad de oportunidades para educarse, ejercer su vida en sociedad, libremente, determinando y desarrollando su propia personalidad y capacidades, pocas personas estarán en contra de este movimiento.

Sin embargo, la imagen de la feminista se ha asociado muchas veces a reclamaciones que van más allá de lo anteriormente expresado, creando un modelo que incluso para muchas mujeres hoy suscita rechazo. Quizás porque al definirse frente a un "tipo cerrado" de lo que es ser varón o masculino, no ha logrado integrar todas las dimensiones que configuran el ser mujer, y no ha sido permeable a la redefinición contemporánea de los roles que se dan vivencialmente tanto en la familia como en la sociedad. Por eso muchas versiones del feminismo pueden cometer el error de asumir sólo un modelo de realización humana y de desarrollo personal tradicionalmente masculino- que incluso ahora no responde a la jerarquía 
de valores que los varones buscan realizar en sus vidas ${ }^{9}$. Y rechazan una serie de dimensiones (como la realización de la afectividad en familia, el cuidado, la solicitud, la construcción de nexos afectivos y personales sólidos y estables) que muchas personas no quieren dejar fuera de sus presentes ni de sus futuros.

De hecho, hoy más que nunca, más allá de las reivindicaciones para una igualdad de oportunidades de desarrollo personal y profesional para ambos sexos (feminismo de la igualdad), se está cuestionando la dirección asumida por el feminismo de los últimos años (feminismo de la diferencia), se está criticando un feminismo que no vaya acompañado de una revisión del papel del hombre en la sociedad actual (tercer feminismo, de la complementariedad, cuya meta está todavía para alcanzar para las mujeres, para todas las mujeres y también para los hombres; Freedman, 2004, p. 23), e incluso se plantea superar ideológicamente el feminismo en la búsqueda de un humanismo integrador (Durán y Lalaguna, 1992, pp. 233-251; Burggraf, 1991; Ballesteros, 2002, pp. 15-24; Caballé, 2013, p. 25; De Diego, 2008).

\section{UN CAMBIO DE PARADIGMA}

"No soy feminista, apuesto por la mujer, creo en ella", son frases que inician un estudio (Eguíbar, 2003, p. 6); el feminismo "no mola", se lee en otro (Caballé, 2013, pp. 15 y 28); "Yo no soy feminista, algunas mujeres han desenfocado al feminismo" (Caballé, 2013, p. 18). O "Soy humanista, no feminista" (Díaz, 11 de octubre de 2014) como expresión reiterada por una famosa actriz. Estas frases suponen, por lo pronto, una posición que rechaza la deriva de un feminismo que implica el rechazo de todo lo considerado "femenino" (Burggraf, 2000, pp. 13-15), o de un feminismo comprendido o comprometido como pugna dialéctica de género (Beauvoir, 1977, 2009), más allá de la legítima reivindicación de acceso a derechos y posibilidades que

\footnotetext{
${ }^{9}$ Hoy en día pocos padres optan por mantenerse al margen del cuidado y educación de sus hijos, hecho favorecido también por el incremento de beneficios (días tras el nacimiento de un hijo; medidas de conciliación laboral; trabajo desde el hogar), aunque las estadísticas siguen dando una mayor incidencia en mujeres, según el CIS.
} 
acompañan a la dignidad de todo ser humano. Pero con ella se nos abre una obligada reflexión en torno a la mujer.

En los últimos cincuenta años, con los cambios sociales de nuestro mundo y las nuevas estructuras de las sociedades contemporáneas, se han intentado (con variado éxito y acierto) distintos modelos de convivencia y, derivadamente, distintas comprensiones acerca de lo debido a cada uno de los sexos (varón y mujer) y su rol en la familia y la sociedad. No puede dudarse que los arquetipos antiguos (que ni siquiera reflejan un modelo único) carecen de la plasticidad necesaria y reclaman de cada agente la creatividad para diseñar una realización personal lo más rica y profunda en aquellas dimensiones sin las que no puede darse un desarrollo integral de la persona.

Se ha pasado ya una situación de transición que han padecido multitud de mujeres: o bien la dolorosa posición de tener que elegir entre vida familiar o una vida, calificada como "egoísta", de autorrealización personal y profesional fuera del hogar; o en una tercera opción imposible, cumplir con el irreal modelo de la superwoman: la mujer que cumple con detalle y perfección los papeles de madre, esposa y trabajadora cualificada, siguiendo los dos primeros roles tal como habían sido concebidos por generaciones anteriores -que implicaban la permanencia en exclusiva en el hogar-, y realizando el último al modo como había sido representado tradicionalmente por el varón (liberado de las responsabilidades familiares y domésticas más allá de las de llevar un sustento pecuniario) ${ }^{10}$.

El feminismo optó por un igualitarismo radical donde se pierde lo que de original y único puede aportar el mundo femenino, y que se convierte en una trampa: triunfar en ella supone para muchas mujeres dejar de lado facetas no

\footnotetext{
${ }^{10}$ Para algunos autores esto ha supuesto una nueva esclavitud para la mujer: la incorporación al mundo laboral sin modificarlo y sin una real comprensión y esfuerzo por hacerlo compatible con el mundo familiar (que en esa dicotomía estaba reservado exclusivamente a la mujer) ha supuesto en la práctica el esfuerzo de duplicar para la mujer una "jornada laboral": una externa, con las exigencias y requisitos de una dedicación exclusiva y en dura competitividad al adentrarse a las suspicacias de un mundo mayormente masculino; y otra interna, intentando no renunciar a ninguna de las vivencias y dedicaciones ejercidas antaño por las mujeres sin ocupación laborar fuera del hogar. Cfr. Blanca Castilla y Cortázar (1992, p. 219).
} 
reemplazables de la vida personal (Durán y Lalaguna, 2002, p. 243; Ballesteros, 2002, pp. 10-16) ${ }^{11}$.

Efectivamente como señala Russell Hochschild (2008, p. 250): “estamos experimentando el estancamiento de una revolución, una época en que las mujeres han cambiado más rápido que los hombres con quienes conviven o las instituciones donde trabajan hombres y mujeres. El estancamiento de la revolución ha marginado la vida familiar y la ha convertido en un 'segundo turno', a saber: sólo la mujer al cumplir su jornada laboral fuera del hogar, vuelve a él para iniciar una nueva, poniendo sobre sus hombros toda la responsabilidad del hogar y familiar de atención, cuidado y seguimiento de las personas que la incluyen".

Ha sido una generación que ha querido sobrevivir asumiendo dos cargas laborales a veces incompatibles y que suponían, cada una de ellas, una dedicación exclusiva y en solitario: por un lado, ser la principal responsable en la gestión y cuidado del hogar, de la atención en exclusiva a los hijos, sus enfermedades, tareas escolares, educación y desarrollo, la atención y cuidado de mayores y dependientes; por otro lado, cumplir y realizar todas las posibilidades de desarrollo personal, formativo y profesional que nuestro tiempo ha abierto en un mundo diseñado por varones y en dura competencia contra ellos.

Desde ahí que se esté exigiendo un nuevo feminismo, o mejor un revisado humanismo porque, por ejemplo, a propósito de la conciliación (SotoBruna, 2011, p. 65), ésta no es patrimonio exclusivo ni de mujer ni de varón, sino de la comprensión de la propia identidad, el establecimiento de una jerarquía de valores y compromisos, comprender quién se es y qué se hace, para elaborar creativamente un marco de acción ordenado y cotidiano. Ese tercer feminismo, o mejor, optar por un revisado humanismo (puesto que

${ }^{11}$ Se ha pretendido que lograr la igualdad para la mujer significaba incorporarse a un modelo (especialmente de sociedad, económico y laboral) de un individualismo productivo, proponiendo rasgos antitéticos a los definidos como femeninos: la independencia frente a la interdependencia, la agresividad frente al cuidado, la competencia frente a la cooperación, la producción (de realidad objetiva externa) frente a la reproducción (relacional y personal), poniendo a la mujer en el puesto tradicional del varón sin modificarlo y sin dejarle aportar lo específicamente femenino a todos aquellos espacios (sociales, culturales, laborables) a los que se incorporaba. 
redefine también el valor de lo masculino) replantea -aunque todavía haya mucho por hacer en lo práctico-, que ni el hogar, ni la educación o cuidado de los hijos, son tareas exclusivamente femeninas sino tareas familiares, y que ni hombres ni mujeres deben renunciar a impregnar la vida familiar y social de su forma de ver el mundo desde la paternidad y maternidad, desde lo masculino y lo femenino, con sus diferencias y su mutuo enriquecimiento (Sánchez Cabaco, 2004, p. 266). Pues es claro que tanto la familia como la formación, la cultura y el trabajo, son los medios por los cuales toda persona desarrolla y plenifica sus capacidades, encuentra el sentido de la propia vida, se integra en una comunidad, participa en ella y le entrega el valor insustituible de su aportación esencial y personal (Martínez-Echevarría, 2004, p. 147; Caballé, 2013, pp. 276, 290).

$\mathrm{Y}$ es que realizarse como mujer, que no es sino el realizarse como persona en la vida recibida, no supone renunciar a un proyecto profesional ni es incompatible con una independencia, pues como afirmaba Burggraf (2000, p. 22): "no creo que la independencia de la mujer sea el problema de hoy. Al contrario, es una suerte que exista, porque sólo quien es interiormente libre e independiente puede amar y entregarse verdaderamente a los demás". Porque lo importante hoy en día no es qué hace sino cómo se hace, teniendo las distintas opciones y vías posibles abiertas para que pueda seguir el camino que mejor se acomode a su proyecto personal ${ }^{12}$.

Muchas veces la plasticidad y diversidad de las formas vividas antecede a la reflexión. En un mundo donde la asignación de los papeles de distribución de roles en la familia por sexos ha sido superada y lo mismo en el espacio social y laboral donde la atribución de trabajos y funciones no está adjetivada de entrada, es preciso acompañar este hecho y fortalecerlo con una consideración sobre qué significa género (Burggraf, 2004).

Debe decirse que "lo paradójico del caso es que aquella categoría [i.e. la de género] que nació con la intención de deconstruir estereotipos opresores a fin de liberar a mujeres y varones, ha terminado por abolir la realidad ontológico-

\footnotetext{
${ }^{12}$ Burggraf (2000, p. 37). Es una noción que incorpora una concepción de posibilidad asociada a libertad realmente enriquecida y que es capaz de aunar naturaleza e historicidad como dos dimensiones ineludibles del ser humano; cfr. Cruz Cruz (1995) apoyado en la teoría expresada por Xavier Zubiri.
} 
política de ambos y esencializar en su lugar los estereotipos sexistas hegemónicos, libremente fragmentados y recombinados por las diversidades bio/cis/trans/tecno/post-genéricas" (Binetti, 2021, p. 192). Se ha enquistado lo masculino y lo femenino con estereotipos ya trasnochados, abriendo la identificación de la persona hacia identidades creadas simbólicamente dentro de un amplio abanico de versiones de géneros, dentro de la estructura desustancializada del modelo antropológico postmoderno (Freedman, 2004, p. 116) ${ }^{13}$.

Como bien han señalado algunos autores (Cf. Castilla de Cortázar, 1992) el único punto de partida válido para la cuestión de género es plantear una pregunta anterior: qué es y significa ser persona y, posteriormente, qué significa ser persona-masculina o persona-femenina como dos formas generales que incluyen a su vez una gran riqueza de expresiones y proyectos vitales (Castilla de Cortázar, 1995, p. 69) ${ }^{14}$. Si nos tomamos en serio la tesis de la unidad psico-somática del ser humano, es decir, de que somos una unidad corpóreo-espiritual (un "espíritu en el mundo": Polo, 2007), entonces o la diferencia de sexos es mera diferencia accidental y externa a la persona, o bien modula internamente el ser persona como masculina o femenina.

En este sentido los estudios realizados (recordemos por ejemplo, las citas tanto de Castilla de Cortázar como de Burggraf) vienen a replantear que sólo se es persona siendo varón o mujer, y esto supone comprender el radical antropológico personal no desde la autosuficiencia (MacIntyre, 2001) sino desde la mutua disposición al otro y a los otros partiendo de una igual dignidad, mutua referencia, ayuda (no servidumbre) y complementariedad; sólo

\footnotetext{
${ }^{13}$ Son los modelos de existencia reducida a "existencia líquida", cambiante, inconsistente, definidos como hombre-goma, el hedonista ecléctico o el "último hombre", el individualista narcisista, el "yo modular", el "hombre mecano", el "hombre Ikea", que nos lleva a un "posthumanismo", en que se ha roto la realidad de una "naturaleza" humana (Sánchez Sánchez, 2018, pp. 99-100). Sin desarrollar otra preocupante cuestión: la introducción de la medicina y farmacología para "diseñar el propio cuerpo" ya "liberado de toda rigidez identitaria" (Caballé, 2013, p. 318; Binetti, 2021, pp. 194-196) hacia un transhumanismo. En cambio (Meloni, 2012, p. 221) debe buscarse una nueva representación del sujeto para evitar tanto el esencialismo como el relativismo.

${ }^{14}$ En esta propuesta antropológica deben tenerse en cuenta autores como Julián Marías (1980, 1982, 1994, 1996), Karol Wojtyla (2005, 2006, 2016, 2017) y a Xavier Zubiri $(1984,1986)$ entre otros autores y documentos de la Iglesia.
} 
entonces se puede desarrollar plenamente la humanidad (Burggraf, 2008, pp. 11-14; 2001, pp. 18-29).

Ni la abstracción de definirnos como humanos con independencia de la determinación de género, ni la absolutización del género o del sexo para la autodeterminación de una vida personal son caminos adecuados, si bien sí han sido caminos ensayados y comprobados en su distorsión (Roig, 1986, p. 21; Binetti, 2021, p. 200) porque ofrecen representaciones que sólo empobrecen la existencia de la mujer (Caballé, 2013, p. 323) y de toda la comunidad (Cortina, 2017, p. 80). El ser humano es naturaleza y cultura entrelazadas y en continuidad, una naturaleza que abre unas posibilidades de desarrollo y una cultura forzada a dar respuesta a esas exigencias de cumplimiento, entendiendo que la humana forma de ser y de vivir es hacerlo libre y racionalmente.

El planteamiento de cómo articular la igualdad de derechos, dignidades y oportunidades para el desarrollo humano y personal de una manera integral y no sesgada, con el reconocimiento de las reales diferencias entre varón y mujer, conlleva filosóficamente la aportación de un renovado paradigma de unidad y diferencia, de manera que la unidad no implique uniformidad ni la diferencia oposición (Ballesteros, 2000, pp. 129-136; Scola, 1989; Freedman, 2004, p. 42).

En la práctica, eso supone la superación de una cosmovisión de relación entre géneros basada en la oposición (históricamente defendida por el pensamiento moderno y el idealismo, reactualizada con el discurso del nuevo feminismo que ha permeado una parte importante del ideario colectivo contemporáneo) ${ }^{15}$, donde el par varón-mujer se definía como la relación de dos opuestos: actividad-pasividad, objetivo-subjetivo, público-privado, razónsentimiento, exterioridad-interioridad, abstracto-concreto,... polos opuestos

\footnotetext{
${ }^{15}$ La revisión del panorama de la mujer en la Edad Media (Solé, 1993), que sufrió en Occidente una transformación lenta pero consolidada por la incorporación de las ideas del cristianismo. También señalaba que el mundo medieval tiene una imagen más rica y valorada de la mujer -frente al pensamiento clásico, griego y romano, con una legislación y valoración más restrictiva- especialmente por la novedad que supuso en el pensamiento cristiano, la valoración de la Virgen María como el ser humano más excelso, y el particular papel de la mujer en el Evangelio frente a las concepciones antiguas judías y grecorromanas; cfr. Reinhardt (1993); Saranyana (1993).
} 
sólo reconciliables en una unidad orgánica superior, como el matrimonio o la familia (Cruz Cruz, 1996; Roig, 1986, p. 19ss.). Y también la superación de una concepción donde la diferencia es circunstancial e irrelevante, pidiendo a la mujer que asuma con exclusividad y acríticamente una forma de vivir y de realizar las nuevas funciones tal como ellas han sido ejercidas por el varón, renunciando a vivirlas y a configurarlas con su propia perspectiva, a enriquecerlas con una aportación diferenciada (Castilla de Cortázar, 2011, p. 219).

En esa línea hay valiosos trabajos que han puesto encima de la mesa la exigencia de replantear qué significa lo femenino para la filosofía, la sociología, la psicología, la teología..., más allá de estereotipos cerrados, desde una concepción lo suficientemente radical del ser humano -de la persona como varón y mujer-, como para poder abrir caminos de comprensión del papel que tanto hombres como mujeres deben ejercer en este nuestro tiempo ${ }^{16}$. Debemos "despertar del sueño dogmático de las posverdades y el mito del logos humano creador y nos traigan de vuelta a la fuerza inmanente de ese real que somos las mujeres" (Binetti, 2021, p. 200).

\section{UNA ANTROPOLOGÍA PARA LOS RETOS DE NUESTRO TIEMPO}

Por lo anterior se exige replantear el problema que plantean los nuevos feminismos desde los parámetros de una antropología renovada, que por un lado supere tanto la abstracción como la oposición dialéctica de géneros, y que dé, por otro lado, un marco más profundo al problema al que hombres y mujeres deben enfrentarse. En esta línea podemos advertir los trabajos de

\footnotetext{
${ }^{16}$ Parten del descubrimiento de que no se es neutro a la adquisición de un género socioculturalmente definido, sino que la biología tiene una expresa dinamicidad que marca unas direcciones bien claras para el desarrollo de la personalidad en un entorno abierto y cultural. Los estudios en psicología y neuropsicología han señalado tanto en animales como en humanos la diferencia básica (biológica y psicológica) dada que orienta la adquisición y desarrollo de una personalidad culturalmente significada. Se citan al respecto casos dramáticos como el experimento John/Joana. La antropología no se ha quedado atrás en esta dirección de articular una definición biológica en un proyecto personal, poniendo como referentes los escritos citados de Wojtyla, Stein, Burggraf, Polo, Zubiri, etc. También la teología desde el impulso de Juan Pablo II (Cunha, 2018).
} 
Julián Marías, Jesús Ballesteros, o de los textos —especialmente desde la Sede Pontificia - de Juan Pablo II (1988).

El punto de partida de toda antropología es, por supuesto, la realidad abierta y trascendente de la persona, persona que no se constituye por el género o por el sexo. Sin embargo, esta línea de reflexión sobre la persona como una realidad desvinculada - en particular tal como la realizó la antropología moderna - de todo lo que a priori era inferior a su carácter espiritual, racional y libre - i.e. la corporalidad - llevó a una imagen distorsionada de la realidad personal que fue duramente criticada desde el siglo XIX. La corporalidad no queda fuera en la definición de lo humano, no lo ha sido en la tradición aristotélica, que mejor ha sido capaz de reflejar la unidad: el alma como principio formal del cuerpo implica que no es indiferente la configuración de la corporalidad para la unidad del viviente humano. Todo el ser humano, cuerpo y alma, es lo que configura la persona (Polo, 2007; Burggraf, 2001b).

La relación del ser humano con la corporalidad ha tenido que superar una visión dualista que lo hacía o un mero instrumento o una máquina a disposición de "valores" y "acciones" más altas, o incluso un pesado lastre del que prescindir o mantener en mínimos para que no obstaculizase la realización de las tareas más plenificadoras (superiores). Sin embargo, lejos de habitar o poseer un cuerpo (en sentido platónico o cartesiano), la filosofía quiso recobrarlo para la definición de la persona: existimos a través del cuerpo señalaba Maurice Merleau Ponty (1975; Cf. Burggraf, 2001b, p. 24), o mejor aún somos nuestra corporalidad; y aunque la sobrepasamos, el cuerpo es la manifestación y expresión ante el mundo y ante los demás de un espíritu en el tiempo (Polo, 2007).

Por ello la diferenciación sexual no es una diferenciación accidental sino que, estando implicada en la configuración de organismo y psique, es una de las formas de ser persona ${ }^{17}$. Blanca Castilla de Cortázar, una de las estudio-

${ }^{17}$ Hay distintas caracterizaciones: formas o modos (Zubiri, 1984; 1986), tipos (Polo, 2007; 2015; Sellés, 2008), que se dirigen a una misma caracterización: la persona como unidad previa que tiene una naturaleza o esencia, queda definida en lo que es por la corporalidad y por tanto por la sexualidad. No implica poner a la sexualidad como el elemento último y superior, sino indicar que dicha unidad queda modalmente diferenciada por el hecho de ser- 
sas que más se ha dedicado a los parámetros de una antropología del género, llega a plantear que hay dos formas de ser persona: persona masculina y persona femenina (1992; 1993; 1995; 1996a; 1996b; 1997).

Diferentes: no son iguales en cuanto a lo que pueden aportar, pero sí de igual dignidad que radica en el ser personal (Sellés, 2008, cap. 20, §8). La modificación de la imagen del ser humano que se ha realizado a partir del siglo XX ha pasado por introducir el elemento relacional (y por lo tanto, la sociabilidad, apertura y trascendencia) en la definición constitutiva personal. La ruptura del modelo individualista en la definición de lo humano permitiría entonces comprender el juego de igualdad y diferencia en la definición de persona (Polo, 2015, p. 150) y comprensión en ella de una modalización de género (masculina y femenina). La complementariedad surge entonces sólo desde la comprensión de que estas dos formas aportan un modo de ser diferenciado (Castilla de Cortázar, 1992; Ballesteros, 2002) a la comunidad que originan, y no una unidad de orden (con un término principal y otro derivado), luego no justifica la asignación férreos límites divisorios en actividades, trabajos, roles sociales... sino que posibilita comprender las diversidad formas en que pueden realizarse dichas actividades, trabajos, o roles...

Ha sido precisamente esa confusión entre la adopción de una igualdad en dignidad y posibilidades de desarrollo personal a través (sin renuncias) del trabajo, el estudio y la familia, con la asunción de un modelo cultural masculino lo que ha consagrado aún más no sólo la minusvaloración de lo femenino sino también la consagración de una fractura, cada vez más amplia, entre la vida que debería vivir una mujer moderna y lo que ella personalmente quiere realizar en todas sus dimensiones (Caballé, 2013, pp. 44-46).

$\mathrm{Y}$ es que, como señalaba Leonardo Polo, renunciar a entender qué significa lo femenino es no "supera[r] la conciencia de inferioridad, sino que más bien se consagra. Si la mujer solamente puede superar su inferioridad masculinizándose, entonces el hombre es superior a la mujer. Buscar la igualdad tomando como modelo al varón es contradictorio, porque para ello tendría que dejar de ser mujer, con lo cual estaría reconociendo que lo femenino como tal, de suyo, conlleva inferioridad" (Polo, 2015, p. 150).

varón o ser-mujer. 
En contra, señala este autor, "El planteamiento correcto tendría que ser el contrario: cuanto más mujer sea una, más igual respecto del varón. Mientras más diferentes sean, más iguales serán, porque se trata de una igualdad entre distintos, no de una igualdad entre homogéneos" (Polo, 2015, p. 150).

Es lo que también había promovido en sus trabajos la teóloga Jutta Burggraf (2001b, p. 29): cuando defiende que si la diferencia entre varón y mujer es una diferencia real - a nivel de una metafísica o antropología trascendental, a saber, las dos formas o modos de ser persona - y no sólo una diferencia cultural, entonces sólo siendo mujer es como cumple su personalidad, y no renunciando a ello; sólo así se crea y construye una sociedad realmente integradora y perfeccionadora. El único reto es delimitar cuánto de costumbre y cultura "superable" va asociado a términos como "lo femenino", "ser", "alma", "espíritu", y qué expresiones lo son realmente de la modulación personal femenina.

Por lo pronto, debe negarse que la diferencia de modos de ser persona masculina o femenina vaya asociada a la existencia de capacidades, potencias, facultades o a su desarrollo. No hay capacidades o facultades exclusivas del varón o de la mujer (Burggraf, 2001b, p. 30). Sí hay determinados hechos (como por ejemplo la estructura biopsicológica que sustenta la paternidad y la maternidad) que marcan profundamente (y desde dentro: Binetti, 2021, p. 199), y si bien ser varón y mujer no se reducen a la paternidad y la maternidad biológica, sí manifiestan dos dimensiones espirituales, y modos frecuentes de desarrollar las capacidades y facultades humanas siguiendo características frecuentes (Burggraf, 2001b, p. 33).

En esa línea tiene sentido hablar de diferentes modos de realizar o vivir el ejercicio de las mismas capacidades y facultades que configuran la naturaleza humana, o incluso distintos modos de ser afectados y potenciados por defectos, vicios, cualidades y virtudes que perfeccionan dicha naturaleza (Polo, 2015, pp. 150-151). Y es que las facultades y capacidades, al quedar incorporadas a la dinámica vital personal, se modalizan de manera diferenciada, y aportan a una sociedad construida por hombres y mujeres no una igualdad homogénea sino una diversidad enriquecedora de relaciones: "se dice que la mujer puede ser empresario lo mismo que el varón, pero lo es de un modo distinto, por ser más convocante o reunitiva" (Polo, 2015, p. 151). 
Así, hay modos diversos de ser inteligente (de hecho hoy en día se está privilegiando la existencia y desarrollo de "inteligencias diversas" (Gardner, 1983; Goleman, 1996) superando el modelo de racionalidad que ha sido atribuido al varón (una racionalidad objetiva, separada, desvinculada, cosificante...), por lo que la inteligencia desarrollada por la personalidad de la mujer (más reunitiva, integradora, atenta al detalle y a la captación global de una situación, incluidas las posiciones y modos de ser afectadas de las personas en ella) supone un real enriquecimiento de las relaciones educativas, laborales, etc., y la posibilidad de cambiar modos de ejercicio de roles y funciones muchas veces periclitados (Cortina, 2017, p. 87). En una sociedad cada vez más compleja, más mediatizada, la mujer no puede inhibirse de aportar su capacidad de cuidar y favorecer las relaciones personales en el ejercicio de cualquiera de los oficios y roles sociales, y de aportar su particular genio en todas las dimensiones de nuestra realidad (Juan Pablo II, 1995; Burggraf, 2006, p. 63). Para la mujer, "su intervención en estos ámbitos de la realidad puede favorecer que este mundo sea menos cosificado de lo que el varón considera; un mundo en el cual atender a los componentes subjetivos es importante, hasta tal punto que si eso no se tiene en cuenta se puede llegar a un mundo de complejidades ingobernables por excesiva especialización" (Polo, 2015, p. 153) ${ }^{18}$.

El rechazo de la existencia de un espíritu, psique o alma femenina diferenciada, por parte de muchas intelectuales ${ }^{19}$, lo era porque suponía la pro-

${ }^{18}$ Y continúa la cita: "Quizá la intervención de la mujer en estos asuntos sea entrar a resolver estos problemas por vía personal. ¿En qué se podría notar? En varias cosas, porque la mujer puede ver mejor los componentes que tienen que ver con seres humanos. El hombre está demasiado proyectado, demasiado obsesionado por la gestación de la obra, por lo cual a veces se hace insensible, tosco; ve la cosa tal como es, pero aislada, es decir, sin ver que ahí están comprometidos seres humanos. Por eso aquí la mujer puede intervenir de manera decisiva. [...] Una mujer puede hacer más habitable el mundo humano. Puede remediar los descuidos varoniles, que son de mucha importancia". "Cuando interviene una mujer humaniza” (Polo, 2015, p. 154).

${ }^{19}$ Quizás el ejemplo más cercano sea el de la discípula de Ortega, Rosa Chacel, quien rechaza la "feminización de la mujer" y critica a Simmel (1938) porque presenta la necesidad de "mantener [...] un dualismo radical; reconocer que la existencia femenina tiene otras bases, fluye por cauces radicalmente distintos de la masculina, construir dos tipos vitales, cada uno con su fórmula autónoma" (Savignano, 2010, p. 78), relegando a la mujer a un mundo 
puesta de bases biológicas y psicológicas también diferenciadas y de segundo plano en las que se habían apoyado las prácticas de adscripción diferenciada de roles, juicio y participación en la comunidad, sin tener en cuenta que ese "alma" femenina no diferencia roles sino los modos en que esos roles, funciones, acciones que toda persona tiene que ejercer en una comunidad, pueden vivirse.

\section{FEMINISMO, O MEJOR "NUEVO HUMANISMO"}

Plantear cuál es el papel de la mujer en la sociedad actual, qué se le pide, y qué ha de aportar, no puede realizarse en justicia sin replantear igualmente, superando estereotipos y acartonados tópicos, cuál es también el papel del varón: las nuevas masculinidades (Castilla de Cortázar, 1995). Pocos esposos y padres conciben ya su realización personal sólo desde el espacio laboral y productivo; valoran y buscan formar parte de la vida familiar, la educación de los hijos y el desarrollo de una vida plena a nivel afectivo y personal. Si esto es así, queda reconfigurar un nuevo orden que incluya lo que ambos géneros tienen que aportar tanto en el espacio público como en la familia, en la política y en el espacio laboral (Sanagustín-Fons, Ramírez-Lozan, Peñaflor-Guerra, 2020).

Una vez que han quedado superados los antiguos clichés que sacaban al varón de la familia, y recluían a la mujer a lo doméstico, a golpe de realismo, tras la incorporación de la mujer al espacio público y social - a veces por necesidad, como durante las campañas bélicas; otras veces al encontrar en el mundo laboral o académico una vía de realización persona_-, se hace preciso no sólo redefinir la realización de tareas dentro de la familia, o en el espacio laboral, sino más bien redescubrir la aportación de las personas en la construcción de una comunidad rica y fecunda, y ver en ellas, además de las múltiples riquezas individuales, también las que hay por los dos modos de ser persona: masculina y femenina.

distinto, apartándola de lo público y la cultura. La propuesta de Chacel, tal como la presenta este estudioso va en la línea de lo señalado aquí: "la mujer debe apropiarse del patrimonio cultural de la humanidad, no significa que ésta deba renunciar a producir cultura desde sus propias intensidades y cualidades" (Savignano, 2010, p. 79). 
Como se ha expresado: no hay virtudes o valores masculinos y virtudes o valores femeninos; tampoco hay trabajos masculinos y trabajos femeninos, o tareas masculinas y tareas femeninas, sino modos de vivir una virtud o un valor desde la masculinidad y desde la feminidad, siendo necesario aportar ambos tanto a la familia como a la sociedad (Castilla de Cortázar, 2011). Tal vez, como expresan algunos analistas, la incorporación de la mujer a todos los sectores de la vida académica, política y pública en general haya favorecido la generalización de una sociedad que valora más el elemento relacional sobre el hecho atomístico, el reconocimiento de lo personal sobre la búsqueda de la eficiencia, lo útil y lo objetivo... (Haaland Matláry, 2000), la acción humana sobre la productividad técnica, el cuidado sobre el dominio, la

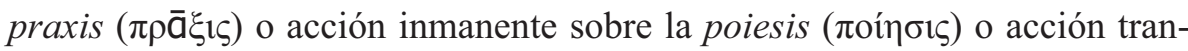
seunte, la finalidad sobre los medios... (Ballesteros, 2002, p. 20). Cambio al que han contribuido las aporías a que ha llevado el desarrollo de una civilización hipertecnificada. Por ello — como se ha afirmado ${ }^{20}$ - tal vez el reto de la sociedad contemporánea será construir una familia con padre y una cultura con madre.

Esto implica la defensa de un "nuevo humanismo" (Llano, 2000; Caballé, 2013, p. 62). No será el humanismo que exalta la autonomía, la libertad y la autoconstitución de la persona como ideal individualizado y abstracto, sino el que se apoya en el carácter relacional y comunitario del ser humano (MacIntyre, 2001). Las propuestas más enriquecedoras en antropología contemporánea han partido de esta constatación básica: el carácter relacional del ser humano no es un elemento posterior y accidental sino aquél en el que se expresa su carácter más propio e identificador, y necesario para comprenderle como persona.

Si el ser humano vive y se desarrolla en una comunidad, construyendo un plexo de relaciones, entonces la vida en común ha de comprenderse desde lo que todas ellas tienen que aportar (MacIntyre, 2001) tanto en la modalización varón-mujer, como en la consideración de las edades (infancia-adultez-

${ }^{20}$ Castilla de Cortázar (2011): "Uno de los mayores descubrimientos antropológicos realizados en el siglo XX es que tanto el varón como la mujer han de contribuir conjuntamente en la construcción familiar y cultural del mundo. Ambos están llamados a ser co-protagonistas del progreso equilibrado y justo que promueva la armonía y la felicidad". 
ancianidad) y circunstancias. Y, para el tema del género y la dualización varón-mujer: enriqueciéndose desde el modo de vivir las virtudes y los valores de hombres y mujeres. Como se ha señalado anteriormente: la modalización sexual de la persona nos ayuda también a entender que el ser personal no se expresa como autosuficiencia; más bien, comprender que se es persona masculina y persona femenina ayuda a entender que la persona hace referencia a una relación y disposición hacia el otro, a que la plenitud se logra en la apertura y referencia hacia los otros, que la mutua referencia es el medio para desarrollar más plenamente la propia humanidad y personalidad (Burggraf, 2008, pp. 13-15; Gonçalves, Silva, 2018; Eguíbar, 2003, p. 6).

Así, en el modo diferenciado de ejercer el trabajo y el cuidado por parte del varón y de la mujer (o con la forma propia de la persona masculina y la femenina), en la familia y en la sociedad, y sin renunciar a lo que cada uno tiene que aportar - especialmente marcado por esa paternidad y maternidad que tanto biológica como espiritualmente configuran las características generales del modo de ser varón y mujer-, es como desde la complementariedad se constituye una sociedad orgánica y enriquecedora.

En fin, al término de este trabajo reitero que no ha sido mi objetivo ni realizar una historia del feminismo ni tampoco mostrar una historia de las ideas, sólo he querido apuntar algunas ideas de la dirección tomada por los nuevos feminismos (post-feminismos) (Burggraf, 2001) y la necesidad de dirigirnos hacia un nuevo humanismo, con el reto de rediseñar funciones, roles y sobre todo aportaciones. Como se ha señalado, no se trata de ocupar un lugar previamente diseñado con valores masculinos, renunciando al modo de ser propio de la mujer, sino más bien, rediseñar la sociedad y la familia para que todos sus miembros aporten y enriquezcan con lo específico de cada uno. En cierto modo, lo que se ha pretendido, apoyado en distintas actitudes y posiciones teóricas, ha sido constatar que hay que redirigir las nuevas propuestas del feminismo o incluso superarlas de sus ataduras ideológicas limitadoras, sin anular lo que de positivo ha tenido dicha lucha por la igualdad de derechos y reconocimientos (Caballé, 2013, p. 302). 
El humanismo revisado quiere ser una versión integradora. Hoy estamos en disposición de lograr una nueva sensibilidad y un nuevo acercamiento al tema del género y de la diferencia sexual que sea capaz de realizar una construcción positiva de un marco social de desarrollo humano. Las bases teóricas ya están puestas; la realización debe superar todavía muchos escollos.

\section{REFERENCIAS BIBLIOGRÁFICAS}

Abad Cadenas, C. (2016). Disidentes y visionarias de los nuevos feminismos. Arbor, 192 (778), 1-9. doi: http://dx.doi.org/10.3989/arbor.2016.778n2011

Agustín Puerta, M. (2003). Feminismo: identidad personal y lucha colectiva. Análisis del movimiento feminista español en los años 35 a 85. Universidad de Granada.

Altera, N. (2021). Sex vs Gender: Plus a practical guide. How to create a gender neutral environment. Nate Altera.

Ballesteros, J. (2000). Postmodernidad y neofeminismo. El equilibrio entre anima y animus. En Postmodernidad: decadencia o resistencia (pp. 129136). Tecnos.

Ballesteros, J. (2002). El paso del feminismo de la igualdad al neofeminismo de la complementariedad como respuesta a los retos de la sociedad contemporánea. En A. Aparisi; J. Ballesteros (eds.). Por un feminismo de la complementariedad. Nuevas perspectivas para la familia y el trabajo (pp. 15-24). Eunsa.

Beauvoir, S. de (1977). El segundo sexo: los hechos y los mitos. Siglo Veinte.

Beauvoir, S. de (2009). La mujer rota. Diario Público.

Binetti, M.J. (2021). Del género a los bio/cis/trans/tecno/post-géneros: el paradójico destino de una extrapolación sociologista, Revista de Investigaciones Feministas 12(1), 191-201.

Burggraf, J. (1991). Los distintos modelos de feminismo. Atlántida.

Burggraf, J. (2000). Vivir y convivir en una sociedad multicultural. Eunsa.

Burggraf, J. (2001a). Hacia un nuevo feminismo para el siglo XXI. Editorial Promesa.

Burggraf, J. (2001b). Una perspectiva cristiana en un mundo secularizado. Editorial Promesa.

Burggraf, J. (2004). ¿Qué quiere decir género? En torno a un nuevo modo de hablar. Editorial Promesa. 
Burggraf, J. (2006). La mujer en Juan Pablo II. En Juan Pablo II y las mujeres. Educa.

Burggraf, J. (2008). Sexualidad humana, verdad y significado. Editorial Promesa.

Caballé, A. (2013). El feminismo en España. La lenta conquista de un derecho. Cátedra.

Castilla de Cortázar, B. (1992). Antropología de la masculinidad-feminidad. En Veinte claves para la nueva era. Rialp.

Castilla de Cortázar, B. (1993). La complementariedad varón-mujer: nuevas hipótesis. Rialp.

Castilla de Cortázar, B. (1995). Persona y modelización sexual. En J. Cruz Cruz (ed.). Metafisica de la familia. Eunsa.

Castilla de Cortázar, B. (1996a). Noción de persona en Xavier Zubiri: una aproximación al género. Rialp.

Castilla de Cortázar, B. (1996b). Persona femenina-persona masculina. Rialp.

Castilla de Cortázar, B. (1997). Persona y género: ser varón y ser mujer. Ediciones Internacionales Universitarias.

Castilla de Cortázar, B. (2011). Trabajo, familia y desarrollo social. Laici.va, 3 octubre 2011.

Cobo, R. (2002). El declive de la postmodernidad: falta de plausibilidad del feminismo postmoderno. La Aljaba 7, pp. 55-77.

Cortina, A. (2017). ¿Valores femeninos, valores masculinos?: el patrimonio axiológico de la humanidad. En F.J. Herrero Hernández, J. Hernández Marcelo (coords.), Virtudes, valores y compromiso social (pp. 79-92). Ediciones de la Universidad Pontificia de Salamanca.

Cruz Cruz, J. (1995). Filosofía de la historia. Eunsa.

Cruz Cruz, J. (1996). Sexualidad y persona: orígenes modernos de un debate sobre el amor, Kant, Fichte y Hegel. Servicio de Publicaciones de la Universidad de Navarra.

Cuenca-Piqueras, C.; González Moreno, M. J.; Checa Olmos, J. C. (2021). ¿Empoderadas u objetivadas? Análisis de las ciberfeminidades en las influencers de moda. Revista de Investigaciones Feministas 12(1), pp. 19-30.

Cunha, J. (2018). Teologia moral e questões de género. Humanistica e Teologia 39(2), pp. 113-126.

De Diego, E. (2008). Feminismo, queer, género, post, revisionismo...: o todo lo contrario. Ser -o no ser- historiador/a del arte feminista en el Estado español. Exit Book: revista de libros de arte y cultura visual 9 pp. 16-23.

Díaz, I. (11 de octubre de 2014). El feminismo es cool. Mujer hoy.

Durán y Lalaguna, P. (1992). Qué feminismo. En Veinte claves para la nueva era. Rialp. 
Eguíbar, M. (2003). La nueva identidad femenina. Palabra.

Folguera, P. (comp.) (1988) El feminismo en España: dos siglos de historia. Editorial Pablo Iglesias.

Freedman, J. (2004). Feminismo ¿unidad o conflicto? Narcea.

Friedan, B. (1974). La mística de la feminidad. Jucar.

Gallego Pérez de Sevilla, F. de B. (2018). Irradiación de poder y transferencia de sacralidad: una reflexión sobre la filosofía moderna y sus consecuencias políticas. Cauriensia 13, pp. 361-394.

Gardner, H. (1983). Inteligencias múltiples. Paidos.

Goleman, D. (1996). Inteligencia emocional. Kairos.

Gonçalves, C.M.; Silva, A.M. (2018). O género e as questões das diferenças identitárias: (in)formar é urgente, amar é essencial. Humanistica e Teologia 39(2), pp. 13-20.

Gouges, Olympe de (1791). Déclaration des droits de la femme et de la citoyenne.

Guerra Palmero, M.J. (2001). Teoría feminista contemporánea. Una aproximación desde la ética. Editorial Complutense.

Haaland Matláry, J. (2000). El tiempo de las mujeres. Notas para un nuevo feminismo. Rialp.

INE (2020). Mujeres y hombres en España 2020. Ministerio de Sanidad, Consumo y Bienestar Social.

Juan Pablo II (1988). Carta apostólica Mulieris dignitatem. Libreria Editrice Vaticana.

Juan Pablo II (1995). Carta a las mujeres. Libreria Editrice Vaticana.

Llano, A. (2000). Humanismo cívico. Ariel.

MacIntyre, A. (2001). Animales racionales y dependientes. Por qué los seres humanos necesitamos las virtudes. Paidós.

Marías, J. (1980). La mujer en el siglo XX. Alianza Editorial.

Marías, J. (1982). Antropología metafisica, en Obras Completas, vol. X, Revista de Occidente.

Marías, J. (1994). Mapa del mundo personal. Alianza Editorial.

Marías, J. (1996). Persona. Alianza Editorial.

Martínez-Echevarría, M.A. (2004). Repensar el trabajo, Ediciones Internacionales Universitarias.

Meloni, C. (2012). Las fronteras del feminismo. Teorías nómadas, mestizas y postmodernas. Edición Fundamentos.

Merleau-Ponty, M. (1975). Fenomenología de la percepción. Península.

Organización de las Naciones Unidas para la Educación, la Infancia y la Cultura (2009). Informe de Seguimiento de la EPT en el mundo 2009. Superar la desigualdad. ONU. 
Polo, L. (2007). Quién es el hombre. Un espíritu en el tiempo. Rialp.

Polo, L. (2015). Epistemología, creación y divinidad. Eunsa.

Reinhardt, E. (1993). Escritoras alemanas en la literatura religiosa medieval. Anuario Filosófico 26(3), pp. 599-620.

Riego de Moine, I. (2008). Identidad y misión de la mujer. El aporte personalista de Edith Stein. En U. Ferrer, Para comprender a Edith Stein. Madrid.

Ritzer, G. (ed.) (2005). Encyclopedia of social theory. Sage Publications.

Roig, M. (1986). El feminismo. Salvat.

Russell Hochschild, A. (2008). La mercantilización de la vida íntima. Apuntes de la casa y el trabajo. Katz Editores.

Sanagustín-Fons, M.V., Ramírez-Lozano, J.P., Peñaflor-Guerra, R. (2020). Feminine and religious leadership. A long term company model. Cauriensia, 15, pp. 771-803.

Sánchez Cabaco, A. (2004). Decálogo para la igualdad. Servicio de Publicaciones de la Universidad Pontificia de Salamanca.

Sánchez Sánchez, T. (2018). La salud como mercado. reflexiones éticas acerca del sobrediagnóstico y el ideal de salud perfecta. En A. Sánchez Cabaco, M. I. Zorroza (eds.). Actualidad de la metafísica. Persona, ciencia y salud. Servicio de Publicaciones de la Universidad Pontificia de Salamanca.

Saranyana, J.I. (1993). Doctrina de la condición femenina en el siglo XII. Anuario Filosófico 26(3), pp. 467-512.

Saranyana, J.I. (2001). Teología de la mujer, teología feminista, teología mujerista y ecofeminisno en América Latina. Editorial Promesa.

Savignano, A. (2010). Ocho miradas al pensamiento español del s. XX. Servicio de Publicaciones de la Universidad de Navarra.

Scola, A. (1989). Identidad y diferencia: la relación hombre-mujer. Encuentro.

Sellés, J.F. (2008). Los hábitos intelectuales según Tomás de Aquino. Eunsa.

Simmel, G. (1938). Cultura femenina: filosofía de la coquetería, lo masculino y lo femenino, filosofía de la moda. Espasa Calpe.

Solé Romeo, G. (1993). La mujer en la Edad Media: una aproximación historiográfica. Anuario Filosófico 26(3), pp. 653-672.

Solé Romeo, G. (2011). Historia del feminismo (siglos XIX Y XX). Eunsa.

Soto-Bruna M.J. (2011). Conciliación y creatividad personal. En Montoro, C. (coord.). Familias con dos sueldos y tres trabajos (pp. 62-83). Instituto de Ciencias para la Familia. Universidad de Navarra.

Stein, Edith (1998). La mujer. Palabra.

Wojtyla, K. (2005). El hombre y su destino. Palabra.

Wojtyla, K. (2006). Mi visión del hombre. Palabra.

Wojtyla, K. (2016). Amor y Responsabilidad. Palabra (6 ed.). 
Wojtyla, K. (2017). Persona y Acción. Palabra (3ª ed.).

Zubiri, X. (1984). El hombre y Dios. Alianza.

Zubiri, X. (1986). Sobre el hombre. Alianza. 